Volume 8. No. 1.1, 2020

International Journal of Emerging Trends in Engineering Research

Available Online at http://www.warse.org/IJETER/static/pdf/file/ijeter1981.12020.pdf

https://doi.org/10.30534/ijeter/2020/1981.12020

\title{
Detection of Multiple Degradations within Polymeric Cable with Multiple Joints
}

\author{
Tze Mei Kuan ${ }^{1}$, Azrul Mohd Ariffin ${ }^{2}$ and Wong Jee Keen Raymond ${ }^{3}$ \\ ${ }^{1}$ Universiti Tenaga Nasional, Malaysia, tzemei@uniten.edu.my \\ ${ }^{2}$ Universiti Tenaga Nasional, Malaysia, azrula@uniten.edu.my \\ ${ }^{3}$ Tunku Abdul Rahman University College, Malaysia, wongjk@tarc.edu.my
}

\begin{abstract}
This paper presents the study on time domain reflectometry (TDR) technique in sectionalizing multiple cable degradations along a polymeric insulated cable with multiple joints. TDR has been widely used for fault localization in polymeric cables. Past studies have found that TDR is able to pinpoint degradation along a cable but they are limited to one degraded cable section only. Hence, this paper investigates the ability of TDR technique to pinpoint two degraded cable sections for an XLPE cable with two joints. This study models a TDR system using MATLAB Simulink with a 300 -metre XLPE cable that is divided into three sections of $100 \mathrm{~m}$ each and then joint together using two cable joints. The location of the two degraded cable sections are varied to study the ability of TDR in detecting degraded cable at different locations. Experiments are conducted with the same cable configurations to validate the simulation results. Findings from both simulation and experimental results show that the TDR technique is also capable of pinpointing multiple degraded cable sections for a cable with multiple jointing.
\end{abstract}

Key words : cable, degradation, insulation, joint, reflectometry

\section{INTRODUCTION}

Power cable introduced in the 1960s have since been widely used for transmission of electrical power. Extruded cable, primarily the cross-linked polyethylene (XLPE) have been increasingly in used for underground distribution system. Due to the growing importance of power cable, it becomes one of the important assets to power utility companies since it is the only channel to supply electricity to the users. Thus, it is crucial for power utility companies to ensure these cables are well maintained to provide a reliable power system.

The rising size of population in the country increases the development activities leading to higher demand in power supply. In order to meet the demand, power utility companies are installing more and more power cables to provide power supply to these areas. Due to the increase in power cable usage over the years, reports on electricity disruption due to power cable failure are increasing at the same time. Power utility companies have been performing various techniques [1-6] of cable diagnosis to prevent cable breakdown. Despite these preventive measures, there are still numerous cases [7-11] of long hours electricity disruption due to power cable failure in the recent years.

To date, power utility companies have been using the time domain reflectometry (TDR) technique to detect faulty cables during cable diagnosis since TDR provides quick response and produces immediate results. However, this technique is only applied after faults has occurred where the cable is in a complete breakdown condition. Replacing the whole faulty cable not only incurs very high cost but at the same time consumes long period of time for the cable replacement works to be completed. Therefore, it is essential to diagnose defects in the cable at the early stage during regular maintenance of power cable by power utility companies to prevent major outages.

Hence, this research investigates the application of TDR technique to detect early insulation degradation in cables so that only the affected cable is replaced rather than replacing the whole cable installed. When only the affected cable is being replaced, lesser time will be taken for the cable replacement work to be completed which directly reduces the electricity disruption time.

\section{LITERATURE REVIEW}

The increasing number of cable breakdowns over the years have led to many researches on polymeric cable diagnostic tests. A number of cable diagnostic tests have been in used which are either destructive or non-destructive tests. However, these cable diagnostic tests are only able to give an overall assessment on the cable which do not predict remaining cable life and pinpoint the fault location [12-14].

TDR is generally used to determine the spatial location and nature of various objects [15]. TDR is a type of reflectometer that has been used as a localization technique in various fields 
Tze Mei Kuan et al., International Journal of Emerging Trends in Engineering Research, 8(1.1), 2020, 120 - 128

such as medical, agriculture and engineering. In medical field, TDR based technique is used for determination of human blood group [16]. The dielectric properties of blood and lag time introduced by the blood sample in the reflected signal are used to identify the blood group. The same principal is also applied in detection of human blood sugar level [17].

In agriculture industry, TDR technique is used to estimate the moisture content in agri-food materials [18-20]. Moisture content is one of the main factors that influences the quality, safety and price of a food product. Hence, the online and offline TDR moisture sensing are used to monitor the water content of materials in the food production line [20]. Besides agriculture, TDR is also applied in civil engineering to measure water content and electrical conductivity in earth materials [21]. Studies in [22-27] have found that the TDR based permittivity measurements is possible to estimate the water content value in raw construction materials.

TDR technique has been used by electrical engineers as an electrical measurement technique for diagnosing hard faults in wires [28-30]. However, studies on the application of TDR technique for fault detection in power cables are still limited. Most of the studies which apply TDR technique for fault detection are conducted on wires and coaxial cables. Studies in [31-33] have shown that TDR is capable of localizing hard faults in aircraft wires and pilot cables such as open circuit and short circuit. However, soft faults such as defects within the cable are not clearly shown on the TDR results.

The application of TDR technique on power cables are studied in [34-36]. However, the technique is also used to characterize severe faults such as open circuit and short circuit. The TDR technique had also been tested on cable joint by [37-39] but no degradation was introduced to the cable joint as well as the cables connected to the joint. The typical TDR reflections on hard faults obtained from these studies [37-39] are illustrated by Figure 1.

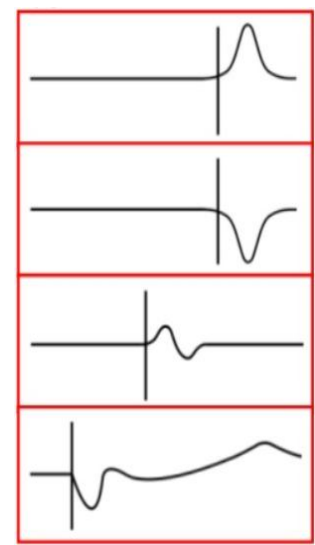

(a) Open conductor

(b) Short conductor

(c) Cable splice or joint

(d) T-joint

Figure 1: Typical TDR Reflections [39]

\section{METHODOLOGY}

Polymeric cable used in this study is the single core $11 \mathrm{kV} 240$ $\mathrm{mm}^{2}$ aluminium conductor XLPE underground cable as per IEC 60502 standard. Since this study focusses on cable with jointing, a 300-metre XLPE cable is used and it is divided into three equal sections of $100 \mathrm{~m}$ and then joint using two cable joints as illustrated in Figure 2.

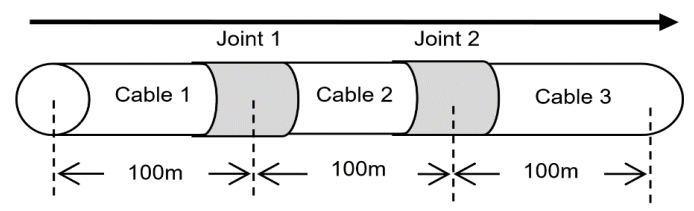

Figure 2: Illustration of Cable Configuration

As this research aims to detect multiple degradations within polymeric insulated cable with multiple joints, the number of degraded cable sections investigated are two and three sections. In order to investigate the capability of TDR in pinpointing the degraded cable section at different locations, a number of cable configurations have been identified as listed in Table 1.

Table 1: TDR Simulation and Experiment Cable Configurations

\begin{tabular}{|c|c|}
\hline $\begin{array}{c}\text { Simulation/ } \\
\text { Experiment }\end{array}$ & Cable Configuration \\
\hline 1 & $100 \mathrm{~m}$ GC joint to $100 \mathrm{~m} \mathrm{GC}$ and $100 \mathrm{~m} \mathrm{GC}$ \\
\hline 2 & $100 \mathrm{~m}$ GC joint to $100 \mathrm{~m} \mathrm{DC}$ and $100 \mathrm{~m} \mathrm{DC}$ \\
\hline 3 & $100 \mathrm{~m}$ DC joint to $100 \mathrm{~m}$ DC and $100 \mathrm{~m} \mathrm{GC}$ \\
\hline 4 & $100 \mathrm{~m}$ DC joint to $100 \mathrm{~m} \mathrm{GC}$ and $100 \mathrm{~m} \mathrm{DC}$ \\
\hline 5 & $100 \mathrm{~m}$ DC joint to $100 \mathrm{~m} \mathrm{DC}$ and $100 \mathrm{~m} \mathrm{DC}$ \\
\hline
\end{tabular}

GC denotes good cable without degradation while DC denotes degraded cable. The cable configuration for Simulation/Experiment 1 having all cable sections in good condition will used as benchmark to compare with other cable configurations with multiple degraded sections. All cable joints in this study are assumed to be in good condition.

In this research, degradation on the XLPE considers contaminant of semiconductor in the insulation layer. Semiconductor is chosen as the contaminant since studies in [40-43] have proven that appearance of semiconductor in the XLPE insulation increases its permittivity level causing the insulation dielectric strength to degrade. Contaminant in cable insulation is chosen as the degradation factor over other factors such as treeing due to time constraint since treeing takes a longer period for it to occur.

As this research comprises of two parts where it begins with simulation work followed by experimental validation, 
Tze Mei Kuan et al., International Journal of Emerging Trends in Engineering Research, 8(1.1), 2020, 120 - 128

degraded cable for the experiment is produced by manufacturing the cable with $5 \%$ semiconductor in the cable insulation which is made of the same material as the conductor screen layer in the cable.

Simulation works are performed using MATLAB Simulink to model the cable and cable joint replicating the actual cable and cable joint, respectively. The four cable configurations from Table 1 are modelled and simulated in MATLAB Simulink to obtain the TDR reflections. These TDR reflections are then analyzed to investigate the reflection characteristics from various cable configurations. Next, TDR experiments are conducted on the same set of cable configurations modelled in MATLAB Simulink. This is to compare the experimental results with simulation results and then to verify the validity of simulation outcomes.

\section{RESULTS AND DISCUSSIONS}

Figure 3 shows the TDR simulation result for Simulation 1 where three $100 \mathrm{~m}$ good cables are connected with two cable joints. Two large reflections are observed at the beginning and at the end which are caused by the large impedance mismatch between both open ends and the cable at the start and the end of the cable, respectively. Besides that, two pairs of cable joint reflections are recorded at $100 \mathrm{~m}$ and $200 \mathrm{~m}$ which clearly point out the first cable joint at $100 \mathrm{~m}$ and the second cable joint at $200 \mathrm{~m}$, respectively. These reflection pairs are identified to be cable joint reflections since each pair comprises of a positive amplitude reflection followed by a negative amplitude reflection where the signature of this reflection pair has been verified by study in [44] which represents a cable joint.

The first pair of cable joint reflections show same magnitudes for both positive and negative reflections suggesting that the impedance difference between the first cable joint and cable 1 are the same as the impedance difference between cable 2 and the first cable joint. No delay is observed for the first cable joint reflection. Hence, this implies that both cable 1 and cable 2 are in good condition. The same characteristics are observed at the second cable joint reflection where no delay is observed and both magnitudes of the positive and negative cable joint reflections are the same. This shows that cable 2 and cable 3 are also having the same cable condition which are all good cables. The simulation result in Figure 3 is compared to the TDR experimental result shown in Figure 4.

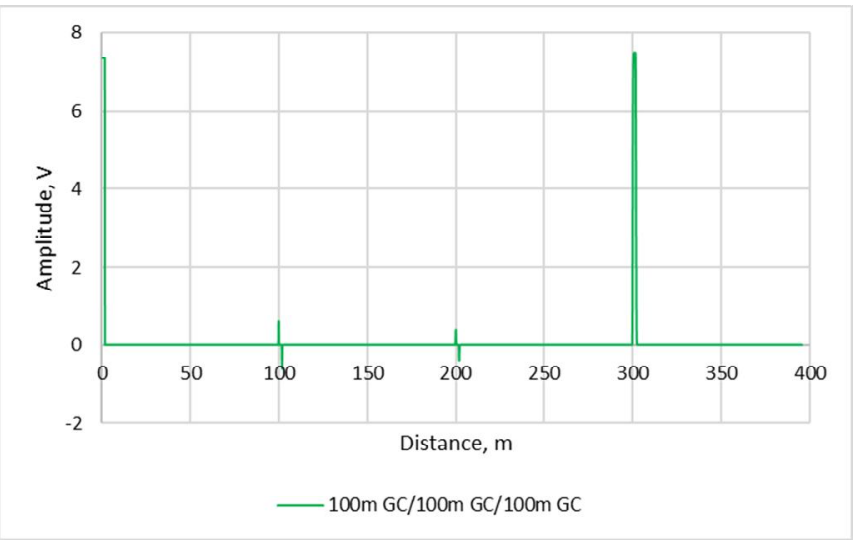

Figure 3: TDR Simulation Result for Simulation 1

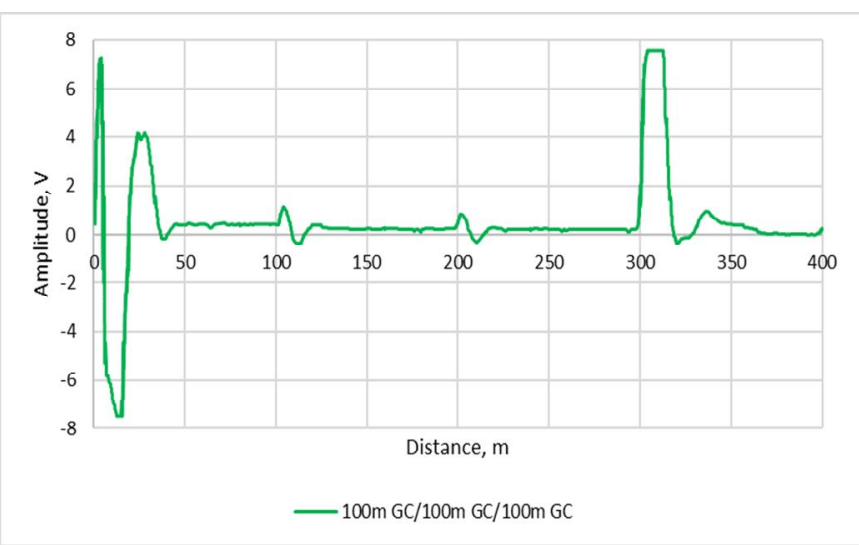

Figure 4: TDR Experimental Result for Experiment 1

The TDR experimental result in Figure 4 shows consistent result with the simulation result in Figure 3 . The reflections due to injected pulse and cable endpoint are also observed. In addition to that, cable joint reflections are detected at $100 \mathrm{~m}$ and $200 \mathrm{~m}$ which are showing the exact same locations as the cable joint installed to these cables without any delay. The amplitudes for the positive and negative cable joint reflections are almost the same for both cable joint reflections which are consistent with the simulated results. There are no drastic differences in the amplitudes for each pair of the cable joint reflections, therefore, the impedance difference between the cable joint and the cable connected before and after the cable can be assumed to be the same. Thus, same cable condition for all three cables are concluded where they are all in good conditions since no delay is observed.

Figure 5 shows the TDR simulation result for Simulation 2 where cable 2 and cable 3 are degraded. This TDR simulation result is validated with TDR experimental result in Figure 6 which is obtained from the same cable configuration as Simulation 2. 
Tze Mei Kuan et al., International Journal of Emerging Trends in Engineering Research, 8(1.1), 2020, 120 - 128

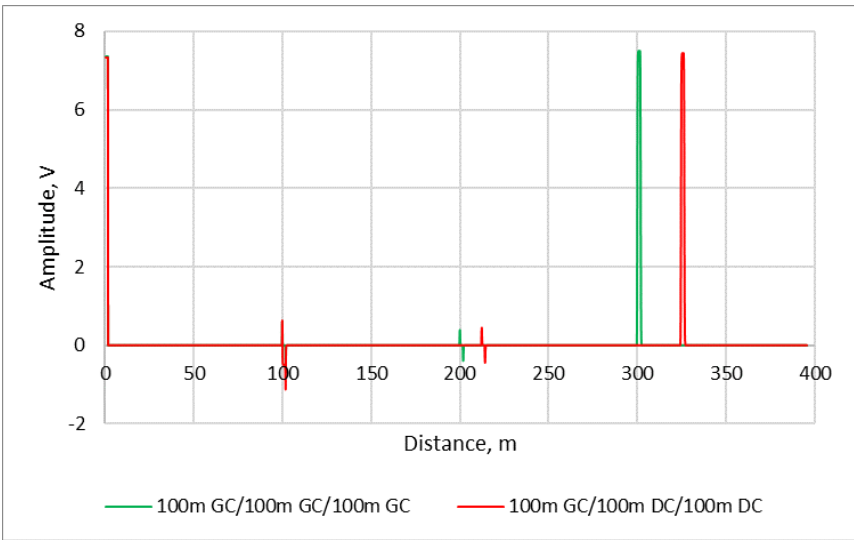

Figure 5: Comparison of TDR Simulation Result for Simulation 2 with Simulation 1

From Figure 5, since cable 1 is in good condition, the first cable joint is reflected very close to $100 \mathrm{~m}$ without delay. Cable 2 and cable 3 are degraded, therefore, a delay is observed at the second joint reflection while the cable endpoint is reflected about twice the delay recorded at the second joint since the signal travels through a longer distance of degraded cable by the time it reaches the cable endpoint. Cable 1 and cable 2 are in different conditions, thus a greater magnitude is observed at the negative reflection of the first cable joint since the degradation in cable 2 creates larger impedance mismatch between the cable and the first joint. Whereas, the second cable joint shows same magnitudes for both positive and negative reflections since the condition of cable 2 and cable 3 are the same, creating the same amount of impedance mismatch between these cables and the second joint.

Both results from Figure 5 and Figure 6 show similarities in the delays observed at the second cable joint and cable endpoint reflections, implying cable 2 and cable 3 are degraded. No delay is observed at first cable joint which indicate cable 1 in good condition. The delay at the cable endpoint is also almost double the delay at the second cable joint. This proves that the amount of reflection delay is dependent on the length of degraded cable. A huge difference in the first cable joint reflection between the positive and negative magnitudes clearly indicates the difference in the impedance mismatch between cable 1 and the first joint, and cable 2 with the first joint. As cable 2 is degraded, hence, higher negative amplitude is observed. At the second joint reflection, both positive and negative reflections show very close magnitudes since both cables connected to the second joint are having the same condition, thus impedance mismatch between these cables and the second joint are similar.

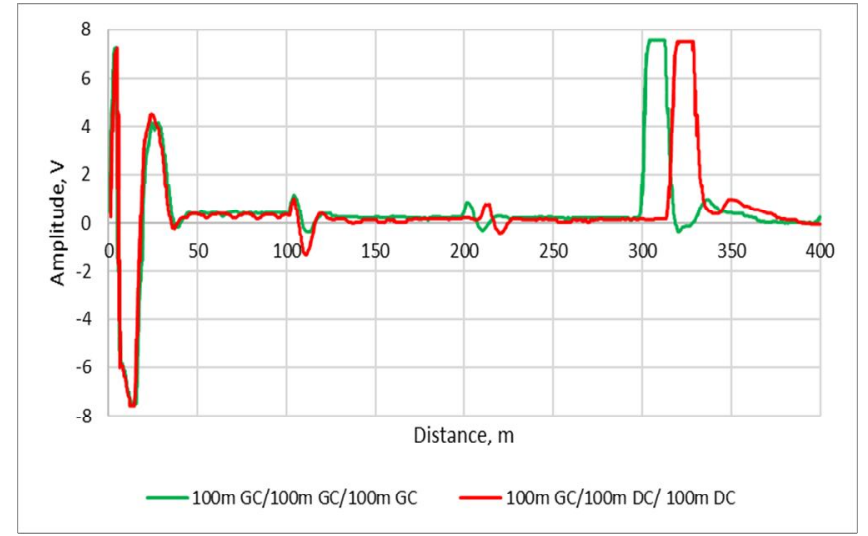

Figure 6: Comparison of TDR Experimental Result for Experiment 2 with Experiment 1

Figure 7 shows the TDR simulation result from Simulation 3 where degraded cables are located at cable 1 and cable 2 while Figure 8 shows the TDR experimental result from the same cable configuration.

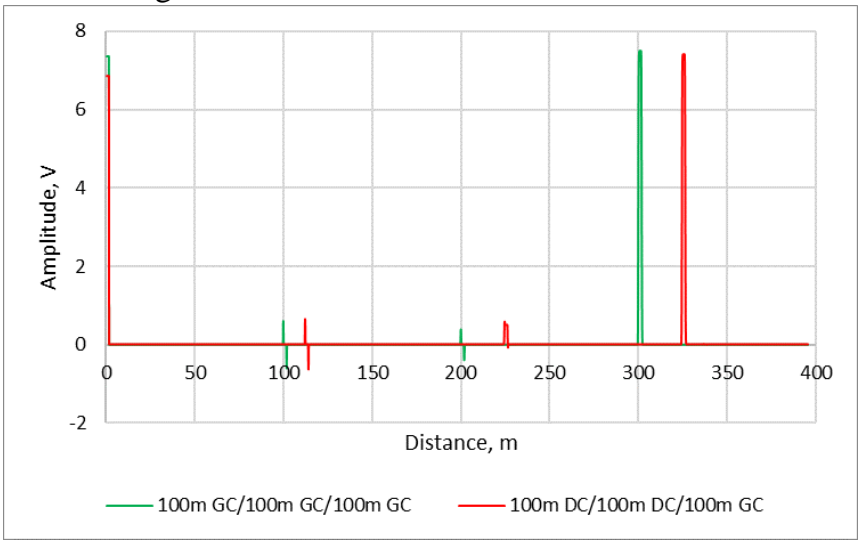

Figure 7: Comparison of TDR Simulation Result for Simulation 3 with Simulation 1

From Figure 7, as the first cable is degraded, delays are observed at both cable joints and cable endpoint reflections. The first cable joint is reflected about $12.26 \mathrm{~m}$ away from the original location of $100 \mathrm{~m}$ while the second cable joint is reflected about $24.43 \mathrm{~m}$ away from $200 \mathrm{~m}$. The delay observed at the second joint is almost double the delay in the first cable joint since the distance travelled by the signal in degraded cable as it reaches the second joint is also twice the distance travelled at first joint. The delay observed at the cable endpoint reflection is the same as the delay at the second cable joint since cable 3 is in good condition which does not contribute to additional delay to the reflection. The first cable joint shows a pair of reflections with the same magnitudes in its positive and negative amplitudes due to the same conditions of cable 1 and cable 2. Degradation in cable 2 causes greater impedance mismatch between the cable and second joint which results in higher positive amplitude at the second joint compared to the negative amplitude since cable 3 is in good condition. This simulation result is validated against the TDR experimental result shown in Figure 8. 
Tze Mei Kuan et al., International Journal of Emerging Trends in Engineering Research, 8(1.1), 2020, 120 - 128

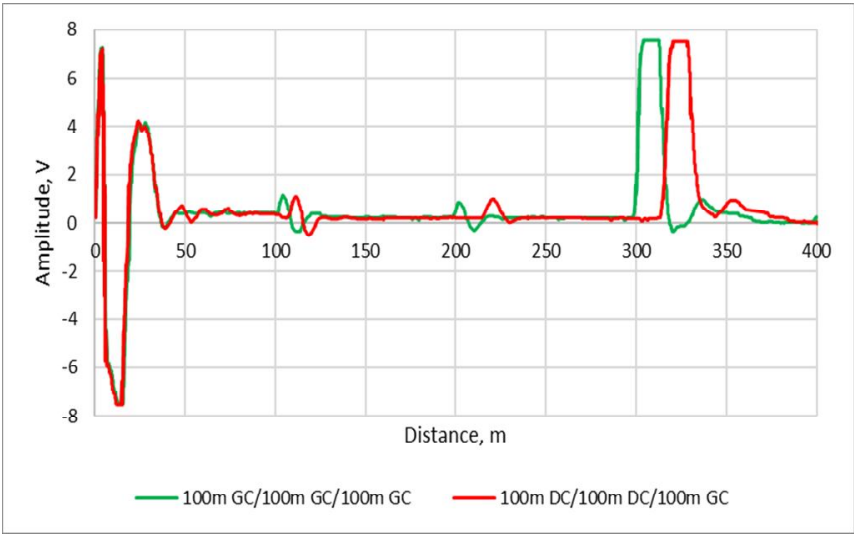

Figure 8: Comparison of TDR Experimental Result for Experiment 3 with Experiment 1

Figure 8 shows the TDR experimental result obtained from Experiment 3. Consistencies are still observed between both simulation result from Figure 7 and experimental result in Figure 8. Reflections from both cable joints and cable endpoint are delayed since the first cable is degraded. Further delay is observed at the second joint as the second cable is also degraded. Delay at the cable endpoint is the almost similar to the delay at the second joint which suggests that the third cable is not degraded. Due to the same cable conditions in cable 1 and cable 2, the magnitudes of the positive and negative reflections at the first joint are about the same. However, significant difference in amplitude is observed at the second joint with the positive reflection showing greater amplitude due to the higher impedance mismatch between cable 2 and second joint since cable 2 is degraded.

TDR simulation result for Simulation 4 is displayed in Figure 9 where cable 1 and cable 3 are degraded. Reflections at both cable joints and cable endpoint are delayed which indicate the first cable is degraded. No further delay is observed at the second cable joint which suggests that the second cable is in good condition. However, the delay at cable endpoint reflection shows about two times the delay observed at the two joints. This additional delay shows that the third cable is degraded. Besides evaluating the delay, the cable condition can also be recognized from the amplitudes of cable joint reflections. The positive reflection at the first cable joint which shows higher amplitude compared to the negative reflection suggests that cable 1 is degraded while cable 2 is in good condition. The same analysis can be conducted at the second joint where the negative reflection now shows higher amplitude compared to the positive reflection indicating cable 3 is degraded while cable 2 remained in good condition.

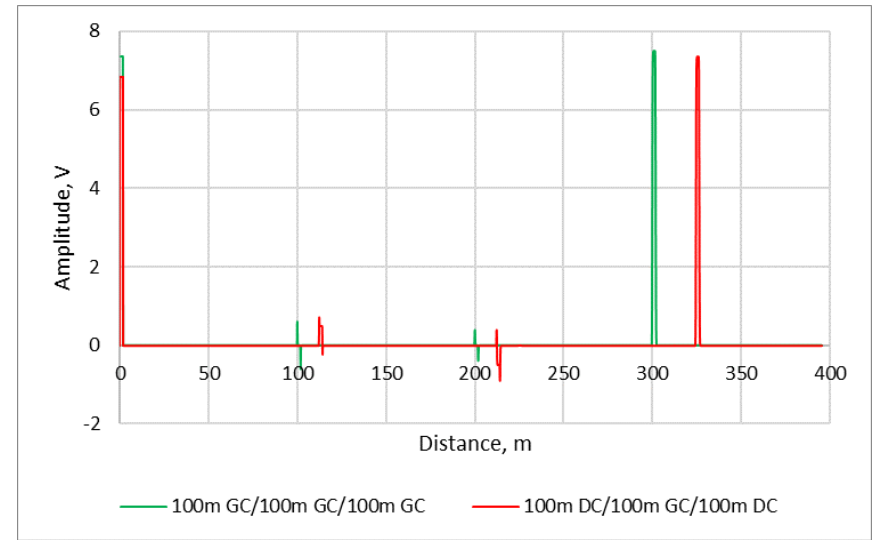

Figure 9: Comparison of TDR Simulation Result for Simulation 4 with Simulation 1

Figure 9 TDR simulation result is compared to the TDR experimental result from Experiment 4 as displayed in Figure 10. The experimental result shows similar characteristics of TDR reflection where delays are observed at both cable joints and cable endpoint reflections. Delays in both cable joints are about the same but since the delay is first observed at the first cable joint, therefore, cable 1 is degraded while cable 2 is in good condition as it does not contribute to additional delay at second joint.

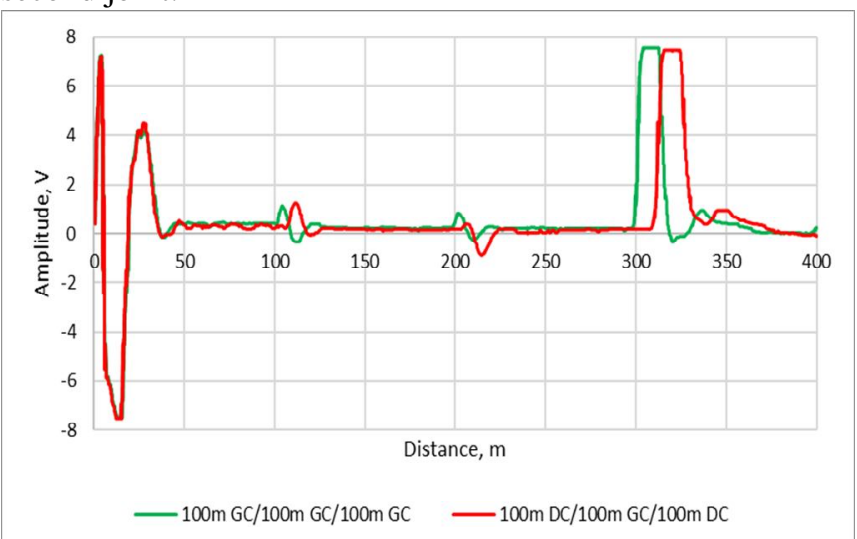

Figure 10: Comparison of TDR Experimental Result for Experiment 4 with Experiment 1

However, the delay at cable endpoint in Figure 10 shows almost twice the delay at both cable joints indicating cable 3 is degraded. Similarly to the simulation result, the cable condition in Figure 10 can also be identified from the amplitudes of the cable joint reflections besides evaluating the delay. The higher amplitude shown by the positive reflection compared to negative reflection at the first joint suggests that cable 1 is degraded while cable 2 is in good condition. At second joint, the negative amplitude is higher compared to the positive amplitude, hence, cable 3 is degraded while cable 2 is not degraded.

Figure 11 shows the TDR simulation result from Simulation 5 where all three cables are in degraded condition. Degradation 
Tze Mei Kuan et al., International Journal of Emerging Trends in Engineering Research, 8(1.1), 2020, 120 - 128

in cable 1 causes delay in the first cable joint reflection. Additional delay is observed at the second cable joint indicating the second cable is also degraded. Further delay observed at cable endpoint which is about three times the delay recorded at the first joint shows that the third cable is also degraded. Since all three cables are having the same degraded condition, the impedance difference between the degraded cables and the joint are the same. Hence, both positive and negative amplitudes are showing the same magnitudes for both joints. This simulation result is compared to the TDR experimental result from Figure 12 for validation.

TDR experimental result in Figure 12 shows consistencies with the TDR simulation result in Figure 11. Delays are also observed at both cable joints and cable endpoint reflections. Delay in the first joint shows that the first cable is degraded. The delay at second joint which shows almost two times the delay at the first joint suggests that the second cable is also degraded. The condition of third cable can be identified from additional delay at the cable endpoint reflection indicating that the third cable is also degraded. The magnitudes of both positive and negative reflections at each joint are observed to be the same since all cables connected to both joints are in the same degraded condition.

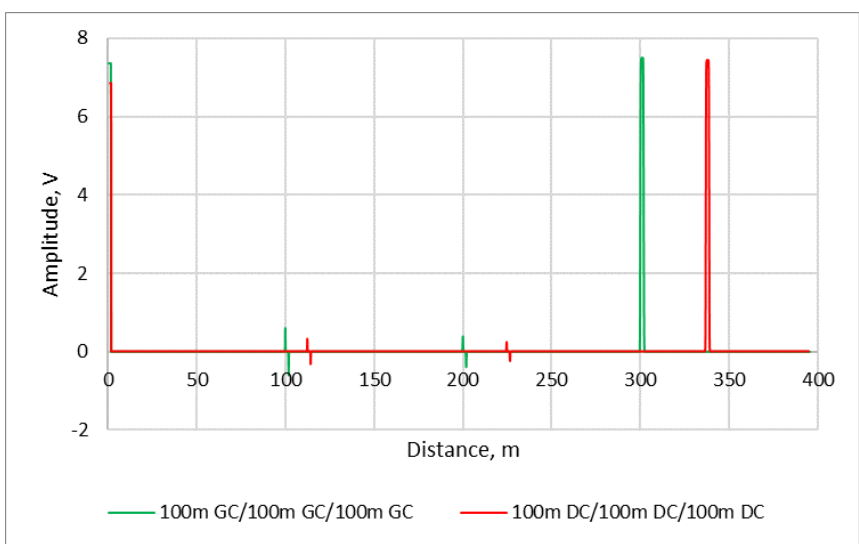

Figure 11: Comparison of TDR Simulation Result for Simulation 5 with Simulation 1

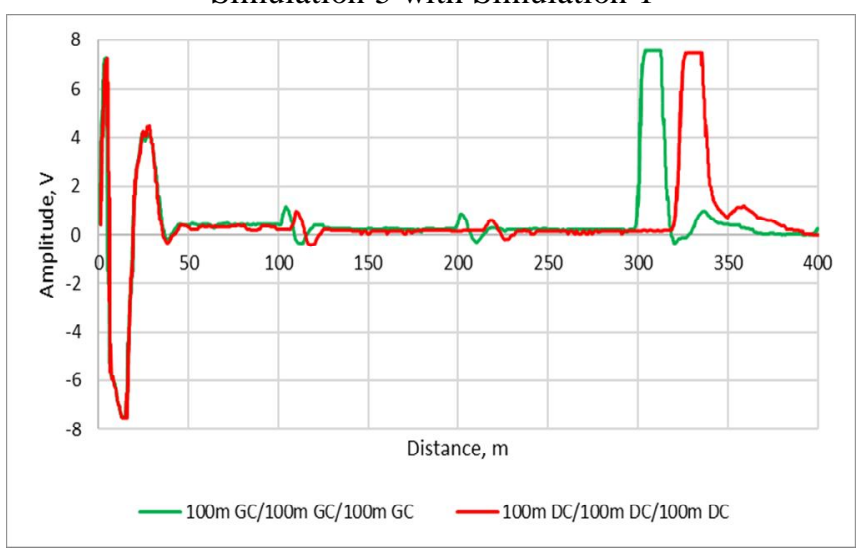

Figure 12: Comparison of TDR Experimental Result for Experiment 5 with Experiment 1
Percentage error is calculated for reflections at $100 \mathrm{~m}, 200 \mathrm{~m}$ and $300 \mathrm{~m}$ as shown in Table 2 to Table 4 . These percentage errors for all three reflections are still found to be within the range of $0 \%$ to $5 \%$ which are considered to be low and are still within the maximum error tolerance of $10 \%$ due to attenuation in the signal as approximated by studies in [45-47]. Therefore, it can be concluded that the methodology in obtaining the parameters to model the good and degraded cables are valid. The assumptions and calculations performed to model the cable joint with inductance correction are also proven to be valid through the verifications of all simulated TDR results which are consistent with the TDR experimental results.

Table 2: Percentage Error at Cable Joint 1 Reflection

\begin{tabular}{|c|c|c|c|c|}
\hline $\begin{array}{c}\text { Simulatio } \\
\mathrm{n}\end{array}$ & $\begin{array}{c}\text { Original } \\
\text { joint } \\
\text { location } \\
(\mathrm{m})\end{array}$ & $\begin{array}{c}\text { Simulated } \\
\text { joint } \\
\text { location } \\
(\mathrm{m})\end{array}$ & $\begin{array}{c}\text { Experimental } \\
\text { joint location } \\
(\mathrm{m})\end{array}$ & $\begin{array}{c}\text { Error } \\
(\%)\end{array}$ \\
\hline 15 & 100 & 100.00 & 100.00 & 0 \\
\hline 19 & 100 & 100.00 & 100.00 & 0 \\
\hline 20 & 100 & 112.26 & 107.76 & 4.18 \\
\hline 21 & 100 & 112.26 & 107.64 & 4.29 \\
\hline 22 & 100 & 112.26 & 108.64 & 3.33 \\
\hline
\end{tabular}

Table 3: Percentage Error at Cable Joint 2 Reflection

\begin{tabular}{|c|c|c|c|c|}
\hline $\begin{array}{c}\text { Simulatio } \\
\mathrm{n}\end{array}$ & $\begin{array}{c}\text { Original } \\
\text { joint } \\
\text { location } \\
(\mathrm{m})\end{array}$ & $\begin{array}{c}\text { Simulated } \\
\text { joint } \\
\text { location } \\
(\mathrm{m})\end{array}$ & $\begin{array}{c}\text { Experimental } \\
\text { joint location } \\
(\mathrm{m})\end{array}$ & $\begin{array}{c}\text { Error } \\
(\%)\end{array}$ \\
\hline 15 & 200 & 200.00 & 200.00 & 0 \\
\hline 19 & 200 & 212.26 & 208.58 & 1.76 \\
\hline 20 & 200 & 224.43 & 214.16 & 4.66 \\
\hline 21 & 200 & 212.26 & 207.43 & 2.33 \\
\hline 22 & 200 & 224.43 & 216.29 & 3.76 \\
\hline
\end{tabular}

Table 4: Percentage Error at Cable Endpoint Reflection

\begin{tabular}{|c|c|c|c|c|}
\hline $\begin{array}{c}\text { Simulatio } \\
\mathrm{n}\end{array}$ & $\begin{array}{c}\text { Original } \\
\text { cable } \\
\text { length } \\
(\mathrm{m})\end{array}$ & $\begin{array}{c}\text { Simulated } \\
\text { cable } \\
\text { length }(\mathrm{m})\end{array}$ & $\begin{array}{c}\text { Experimental } \\
\text { cable length } \\
(\mathrm{m})\end{array}$ & $\begin{array}{c}\text { Error } \\
(\%)\end{array}$ \\
\hline 15 & 300 & 300.00 & 300.00 & 0 \\
\hline 19 & 300 & 324.43 & 314.47 & 3.17 \\
\hline 20 & 300 & 324.43 & 314.11 & 3.29 \\
\hline 21 & 300 & 324.43 & 313.77 & 3.40 \\
\hline 22 & 300 & 336.60 & 324.41 & 3.76 \\
\hline
\end{tabular}

Table 5 summarizes the characteristics of TDR reflections at first and second cable joints where the cable condition can be distinguished from these signatures. 
Tze Mei Kuan et al., International Journal of Emerging Trends in Engineering Research, 8(1.1), 2020, 120 - 128

Table 5: Signatures of Cable Joint Reflections

\begin{tabular}{|c|c|c|c|c|}
\hline \multirow{2}{*}{$\begin{array}{c}\text { Cables } \\
\text { Condition } \\
\mathrm{s}\end{array}$} & \multicolumn{2}{|c|}{$\begin{array}{c}\text { Cable Joint } 1 \text { (CJ1) } \\
\text { Reflection }\end{array}$} & \multicolumn{2}{|c|}{$\begin{array}{c}\text { Cable Joint } 2(\mathrm{CJ} 2) \\
\text { Reflection }\end{array}$} \\
\hline & $\begin{array}{c}\text { Simulatio } \\
\text { n Result }\end{array}$ & $\begin{array}{l}\text { Exp. } \\
\text { Result }\end{array}$ & $\begin{array}{c}\text { Simulatio } \\
\text { n Result }\end{array}$ & $\begin{array}{l}\text { Exp. } \\
\text { Result }\end{array}$ \\
\hline $\begin{array}{l}\text { Good } \\
- \text { CJ1 - } \\
\text { Good } \\
\text { - CJ2 - } \\
\text { Good }\end{array}$ & & & & \\
\hline $\begin{array}{c}\text { Good } \\
\text { - CJ1 - } \\
\text { Degraded } \\
\text { - CJ2 - } \\
\text { Degraded }\end{array}$ & & & & \\
\hline $\begin{array}{c}\text { Degraded } \\
\text { - CJ1 - } \\
\text { Degraded } \\
\text { - CJ2 - } \\
\text { Good }\end{array}$ & & & 1 & \\
\hline $\begin{array}{c}\text { Degraded } \\
\text { - CJ1 - } \\
\text { Good } \\
\text { - CJ2 - } \\
\text { Degraded }\end{array}$ & & & & \\
\hline $\begin{array}{c}\text { Degraded } \\
\text { - CJ1 - } \\
\text { Degraded } \\
\text { - CJ2 - } \\
\text { Degraded }\end{array}$ & 1 & & $\lambda_{1}$ & $\sim$ \\
\hline
\end{tabular}

\section{CONCLUSION}

Results from this research have shown that a cable joint can still be identified from the TDR reflection through a pair of reflections comprising of a positive reflection followed by a negative reflection which is consistent with findings from previous study to detect single degraded cable section. Findings from this study also proves that a cable with multiple joints having multiple degraded cable sections can still be pointed out from the cable joint reflection with the same theory where a degraded cable creates a greater impedance mismatch between the cable impedance and the cable joint impedance resulting in higher amplitude in the reflection.

Thus, a higher positive joint reflection indicates the cable before the joint is degraded while a higher negative joint reflection suggests the cable after the joint is degraded. A delay will be observed at the cable joint reflection when a degraded cable is connected before the joint. Therefore, when there are two consecutive degraded cable sections, further delay will be observed at the second joint.
Hence, with these verified signatures of TDR reflections for both good and degraded cables and the cable joint, degradation in a cable can be easily pinpointed using TDR technique to reduce the duration of cable diagnosis period allowing immediate cable repair works to take place and consequently reducing the electricity disruption time.

Further studies can be conducted on cable configurations with multiple insulation degradation as well as degradation at cable joint to investigate the capability of TDR technique in pinpointing degraded cable insulation and degraded cable joint.

\section{ACKNOWLEDGEMENT}

The authors would like to thank the Universiti Tenaga Nasional, Malaysia for funding this project under the BOLD Research Grant (RJO10517844/047) and the High Voltage Diagnostics team from TNB Research Sdn. Bhd. for their full support in laboratory facilities, technical support and cable samples.

\section{REFERENCES}

1. H. Cao, L. K. Lim, K. X. Lai, C. M. Lip and Y. T. Tan, Condition Monitoring of Distribution Cables using VLF Diagnostic Test with Tangent Delta, Time Domain Reflectometry and Partial Discharge Measurements, 21st Conference of the Electric Power Supply Industry, Bangkok, Thailand, 23-27 October 2016, pp. 1-11.

2. A. Mohd. Ariffin, S. Sulaiman, A. Z. Che Yahya and A. B. Abd. Ghani, Analysis of Cable Insulation Condition using Dielectric Spectroscopy and Polarization/Depolarization Current Techniques, 2012 IEEE International Conference on Condition Monitoring and Diagnosis, Bali, Indonesia, 23-27 September 2012, pp. 145-148.

3. N. Ahmed and N. Srinivas, On-line versus Off-line Partial Discharge Testing in Power Cables, 2001 IEEE/PES Transmission and Distribution Conference and Exposition, Vol. 2, Atlanta, GA, USA, 2 November 2001, pp. 865-870.

4. P. Werelius, Development and Application of High Voltage Dielectric Spectroscopy for Diagnosis of Medium Voltage XLPE Cables, Kungl Tekniska Hogskolan, 20 December 2001.

5. D. L. McKinnon, Insulation Resistance Profile (IRP) and Its Use for Assessing Insulation Systems, Conference Record of the 2010 IEEE International Symposium on Electrical Insulation, San Diego, CA, USA, 6-9 June 2010, pp. 1-4.

6. M. K. Smail, Wire Diagnosis using Reflectometry Response and Optimization Method, Wave Propagation, 2014, pp. 473-511. 
Tze Mei Kuan et al., International Journal of Emerging Trends in Engineering Research, 8(1.1), 2020, 120 - 128

7. F. D. L. Torre, Cable failure triggers 3-hour islandwide power outage, Saipan Tribune, 20 August 2018.

8. R. Baines, Tasmanian power crisis: Basslink 'design and operation inadequate', Hydro readying for legal fight, emails reveal, $A B C$ News, 25 February 2018.

9. D. Mears, Electrical Cable Failure Causes Downtown Detroit Explosions, Detroit News, 3 August 2017.

10. E. Gosden, Breakdowns force National Grid to issue power supply crunch alert, The Telegraph News, U.K., 10 May 2016.

11. E. Coulter and R. Baines, Power rationing flagged for industry after delay in Basslink power cable repairs, ABC News, Australia, 14 January 2016.

12. R. Hartlein et. al., Diagnostic Testing of Underground Cable Systems, National Electric Energy Testing Research and Applications Center (NEETRAC), Georgia Tech., December 2010, pp. 1-33.

13. F. Aras, V. Alekperov, N. Can and H. Kirkici, Aging of $154 \mathrm{kV}$ Underground Power Cable Insulation under Combined Thermal and Electrical Stresses, IEEE Electrical Insulation Magazine, Vol. 23, No. 5, 24 September 2007, pp. 25-33.

14. J. Densley, An Overview of Aging Mechanisms and Diagnostics for Extruded Power Cables, IEEE Power Engineering Society Winter Meeting 2000, Singapore, 23-27 January 2000, pp. 1587-1592.

15. C. Furse and R. Haupt, Down to the Wire, IEEE Spectrum, February 2001, pp. 34-39.

16. J. F. Mahdi, S. N. Helambe and N. Akhter, Time Domain Reflectometry (TDR) Based Technique for Detection of Blood Group, Journal of Environmental Science, Computer Science and Engineering \& Technology, Vol. 1, No. 2, pp. 197-204.

17. J. F. Mahdi, S. N. Helambe and N. Akhter, Detection of Human Blood Sugar using Time Domain Reflectometry (TDR) Technique, Journal of Chemical, Biological and Physical Sciences, Vol. 2, No. 3, pp. 1431-1437.

18. M. Vallone, A. Cataldo and L. Tarricone, Water Content Estimation in Granular Materials by Time Domain Reflectometry: A Keynote on Agro-food Applications, IEEE Instrumentation and Measurement Technology Conference, Warsaw, Poland, 1-3 May 2007.

19. A. Cataldo, M. Vallone, L. Tarricone, G. Cannazza and M. Cipressa, TDR Moisture Estimation for Granular Materials: An Application in Agro-Food Industrial Monitoring, IEEE Transactions on Instrumentation and Measurement, Vol. 58, No. 8, August 2009, pp. 2597-2605.

20. A. Cataldo, E. De Benedetto, C. Huebner, D. Trebbels, TDR Application for Moisture Content Estimation in Agri-food Materials, IEEE Instrumentation \& Measurement Magazine, Vol. 20, No. 3, 2017, pp. 26-31.

21. D. Or and S. B. Jones, Time Domain Reflectometry (TDR) Applications in Earth Sciences, IEEE Antennas and Propagation Society International Symposium, San Antonio, TX, USA, 16-21 June 2002.

22. S. Dey, P. Kalasuriya and N. C. Karmakar, A Novel Time Domain Reflectometry based Chipless RFID Soil Moisture Sensor, IEEE MTT-S International Microwave Symposium, Phoenix, AZ, USA, 17-22 May 2015.

23. A. Cataldo, L. Tarricone, M. Vallone, F. Attivissimo and A. Trotta, Uncertainty Estimation in Simultaneous Measurements of Levels and Permittivities of Liquids using TDR Technique, IEEE Transactions on Instrumentation and Measurement, Vol. 57, No. 3, March 2008, pp. 454-466.

24. A. Cataldo, E. De Benedetto, G. Cannazza, E. Piuzzi and E. Pittella, TDR-Based Measurements of Water Content in Construction Materials for in the Field Use and Calibration, IEEE Transactions on Instrumentation and Measurement, Vol. 67, No. 5, May 2018, pp. 1230-1237.

25. I. G. Platt, A. Hayward, I. M. Woodhead and M. Hagedorn, Timber Tomography using Time Domain Reflectometry: First Results, 2012 Sixth International Conference on Sensing Technology, Kolkata, India, 18-21 December 2012.

26. C. A. Umenyiora, R. L. Druce, R. D. Curry, P. Norgard, T. McKee, J. J. Bowders and D. A. Bryan, Dielectric Constant of Sand using TDR and FDR Measurements and Prediction Models, IEEE Transactions on Plasma Science, pp. 2408-2415.

27. I. Platt, I. Woodhead, P. Harrington and A. E. C. Tan, Imaging and Parameterizing Moisture in Road Sub Course using Time Domain Reflectometry, IEEE Sensors Journal, pp. 4760-4766.

28. H. Boudjefdjouf, H. R. E. H. Bouchekara, R. Mehasni, M. K. Smail, A. Orlandi and F. de Paulis, Wire Fault Diagnosis using Time-Domain Reflectometry and Backtracking Search Optimization Algorithm, 2015 31 st International Review of Progress in Applied Computational Electromagnetics, Williamsburg, VA, USA, 22-26 March 2015, pp. 1-2.

29. C. Parkey, C. Hughes and N. Locken, Analyzing Artifacts in the Time Domain Waveform to Locate Wire Faults, IEEE Instrumentation \& Measurement Magazine, Vol. 15, No. 4, 9 August 2012, pp. 16-21.

30. S. Schuet, D. Timucin and K. Wheeler, A Model-Based Probabilistic Inversion Framework for Characterizing Wire Fault Detection using TDR, IEEE Transactions on Instrumentation and Measurement, Vol. 60, No. 5, 7 February 2011, pp. 1654-1663.

31. G. H. Shirkoohi and K. Hasan, Enhanced TDR Technique for Fault Detection in Electrical Wires and Cables, 2nd International Symposium on NDT in Aerospace, 2010, pp. 1-6.

32. Q. Shi and O. Kanoun, A New Algorithm for Wire Fault Location Using Time-Domain Reflectometry, 
Tze Mei Kuan et al., International Journal of Emerging Trends in Engineering Research, 8(1.1), 2020, 120 - 128

IEEE Sensors Journal, Vol. 14, No. 4, April 2014, pp. 1171-1178.

33. M. K. Smail, L. Pichon, M. Olivas, F. Auzanneau and M. Lambert, Detection of Defects in Wiring Networks Using Time Domain Reflectometry, IEEE Transactions on Magnetics, Vol. 46, No. 8, August 2010, pp. 2998-3001.

34. M. Ahmed, M. A. Al-Ohali, M. A. Garwan, K. Y. Soufi and Z. M. Hamouz, How Good are Electrical Diagnostic Tests to Predict Water Trees in HV Cables - An Evaluation using Optical Microscopy, Journal of Electrical Engineering, Vol. 56, No. 1-2, 2005, pp. 31-35.

35. K. W. Burkes, E. B. Makram and R. Hadidi, Water Tree Detection in Underground Cables using Time Domain Reflectometry, IEEE Power and Energy Technology Systems Journal, Vol. 2, No. 2, 8 May 2015, pp. 53-62.

36. K. W. Burkes, Time Domain Reflectometry of a Water Tree inside an Underground Cable, Proceedings of the 2016 COMSOL Conference, 2016, Boston, MA, USA.

37. T. Engdahl, Time Domain Reflectometry (TDR), ePanorama.net, 1999.

38. C. Dodds, Cable Fault Location by Baur, Thorne \& Derrick, 22 February 2016.

39. Data sheet - TDR2000/3 Series, Megger, 2018

40. Q. Pelzer, L. Perrin, P. Notingher, X. Colin, M. Ben-Hassine, A. Resmond and L. Flandin, Aging of Underground Power Cables: Species Migration from Semi-Conductive Layers to the Insulating Layer, IEEE Conference on Electrical Insulation and Dielectric Phenomena, 21-24 October 2018, Cancun, Mexico

41. R. Paludo, G. C. da Silva and V. S. Filho, The Study of Semiconductor Layer Effect on Underground Cables with Time Domain Reflectometry (TDR), IOSR Journal of Electrical and Electronics Engineering, Vol. 7, No. 6, 1 January 2013, pp. 1-7.

42. I. L. Hosier, A. S. Vaughan, A. Campus and U. Nilsson, Morphology of Novel XLPE Cable System, IEEE International Conference on Solid Dielectrics, 8-13 July 2007, Winchester, UK.

43. T. Liu, J. Fothergill, S. Dodd and U. Nilsson, Influence of Semicon Shields on the Dielectric Loss of XLPE Cables, IEEE Conference on Electrical Insulation and Dielectric Phenomena, 18-21 October 2009, Virginia Beach, VA, USA.

44. T. M. Kuan, S. Sulaiman, A. Mohd. Ariffin and W. M. S. Wan Shamsuddin, Verification of MATLAB/Simulink Power Cable Modelling with Experimental Analysis, Indonesian Journal of Electrical Engineering and Computer Science, Vol. 11, No. 2, August 2019, pp. 622-629.

45. P. Wagenaars, P. A. A. F. Wouters, P. C. J. M. van der Wielen and E. F. Steennis, Measurement of Transmission Line Parameters of Three-core Power Cables with Common Earth Screen, IET Science, Measurement and Technology, Vol. 4, No. 3, 2010, pp. 146-155.
46. R. Papazyan and R. Eriksson, Calibration for Time Domain Propagation Constant Measurement on Power Cables, IEEE Transactions on Instrumentation and Measurement, Vol. 52, No. 2, April 2003.

47. P. C. J. M. Van Der Wielen, On-line Detection and Location of Partial Discharges in Medium-Voltage Power Cables, PhD Thesis, Eindhoven University of Technology, 2005. 